\title{
Dicer-1 and R3D1-L catalyze microRNA maturation in Drosophila
}

\section{Feng Jiang, ${ }^{1,3}$ Xuecheng Ye, ${ }^{1,3}$ Xiang Liu, ${ }^{1}$ Lauren Fincher, ${ }^{1}$ Dennis McKearin, ${ }^{2}$ and Qinghua Liu ${ }^{1,4}$}

${ }^{1}$ Department of Biochemistry, ${ }^{2}$ Department of Molecular Biology, University of Texas Southwestern Medical Center, Dallas, Texas 75390, USA

In Drosophila melanogaster, Dicer-2/R2D2 and Dicer-1 generate small interfering RNA (siRNA) and microRNA (miRNA), respectively. Here we identify a novel dsRNAbinding protein, which we named R3D1-L, that forms a stable complex with Dicer-1 in vitro and in vivo. While depletion of R3D1-L by RNAi causes accumulation of precursor miRNA (pre-miRNA) in S2 cells, recombinant R3D1-L enhances miRNA production by Dicer-1 in vitro. Furthermore, R3D1 deficiency causes miRNA-generating defect and severe sterility in male and female flies. Therefore, R3D1-L functions in concert with Dicer-1 in miRNA biogenesis and is required for reproductive development in Drosophila.

Supplemental material is available at http://www.genesdev.org.

Received May 17, 2005; revised version accepted May 27, 2005.

RNA interference (RNAi) is a form of post-transcriptional gene silencing guided by 21-25-nucleotide (nt) small RNA molecules (Hannon 2002). At least two classes of small RNA, small interfering RNA (siRNA) and microRNA (miRNA), have been described (Tang 2005; Tomari and Zamore 2005). These tiny regulatory RNAs play essential roles in many biological processes, such as development, antiviral defense, heterochromatin formation, and maintenance of genomic stability (Hannon 2002; Bartel 2004).

The RNAi pathway consists of initiation and effector steps. First, siRNA and miRNA are generated from mostly exogenous long dsRNA and endogenous short hairpin precursor miRNA (pre-miRNA), respectively. Second, nascent siRNA and miRNA are assembled into similar but distinct effector complexes termed the RNAinduced silencing complex (RISC) (Hammond et al. 2000, 2001; Okamura et al. 2004). The term "RISC" was initially coined to describe the endonuclease complex harboring siRNA (Hammond et al. 2000). Here we broaden the definition of RISC to include the effector complexes for siRNA and miRNA by simply referring to them as

[Keywords: Dicer-1; R3D1-L; RNase III; dsRNA binding; pre-miRNA; miRNA]

${ }^{3}$ These authors contributed equally to this work.

${ }^{4}$ Corresponding author.

E-MAIL qliu@biochem.swmed.edu; FAX (214) 648-0320.

Article published online ahead of print. Article and publication date are at http://www.genesdev.org/cgi/doi/10.1101/gad.1334005.
siRISC and miRISC (Tang 2005). In RISCs, siRNA/ miRNA functions as the guide RNA for sequence-specific cleavage and/or translational repression of complementary mRNA (Bartel 2004; Tang 2005; Tomari and Zamore 2005).

Both siRNA and miRNA are produced by Dicers, a family of large multidomain RNase III enzymes (Hannon 2002). Although most species, such as Caenorhabditis elegans and humans, contain a single Dicer enzyme, two Dicers, Dicer-1 and Dicer-2, have been found in Drosophila (Bernstein et al. 2001). Genetic studies have suggested that Dicer-1 and Dicer-2 are involved in miRNA and siRNA production, respectively (Lee et al. 2004). We have previously purified the siRNA-generating enzyme from S2 cell extracts and found that it consisted of Dicer-2 and the dsRNA-binding protein R2D2 (Liu et al. 2003). R2D2 forms a heterodimeric complex with Dicer-2 (Liu et al. 2003). Although R2D2 does not regulate siRNA production, it facilitates the role of Dicer-2 in loading siRNA onto siRISC (Liu et al. 2003; Tomari et al. 2004).

Biogenesis of miRNA occurs in a two-step process. In the nucleus, the primary miRNA (pri-miRNA) transcript is processed by the RNase III Drosha into 70-nt stemloop pre-miRNA (Lee et al. 2003). Drosha requires the company of the dsRNA-binding protein Pasha ${ }^{\text {fly }}$ (or DGCR8 $8^{\text {human }}$ ) for processing pri-miRNA (Denli et al. 2004; Gregory et al. 2004; Han et al. 2004; Landthaler et al. 2004). Once generated, pre-miRNA is exported by Exportin 5/RanGTP to the cytoplasm (Yi et al. 2003; Bohnsack et al. 2004; Lund et al. 2004), and is further cleaved by Dicer- $1^{\text {fly }}$ (or Dicerhuman) into 21-22-nt mature miRNA (Hutvagner et al. 2001; Lee et al. 2004).

Both Drosha and Dicer contain tandem RNase III domains that form a single catalytic center to make a pair of cuts at the double-stranded stem of pre-miRNA hairpin, creating a characteristic 2-nt 3' overhang (Han et al. 2004; Zhang et al. 2004). Drosha cleaves at the base of pre-miRNA to liberate it from pri-miRNA and to generate one end of miRNA (Han et al. 2004). Dicer cuts near the loop of pre-miRNA at a 21-22-nt distance from the Drosha cleavage site to excise miRNA from its precursor (Cullen 2004).

In this study, we report three important findings: (1) We establish by reconstitution that Drosophila Dicer-1 and Dicer-2 enzymes display different substrate specificities and ATP requirements. (2) We identify a novel dsRNA-binding protein, which we named R3D1-L that functions as a cofactor for Dicer-1 in miRNA biogenesis. (3) We show that R3D1 deficiency causes a miRNA-generating defect and severe sterility in male and female flies. Taken together, these results indicate that R3D1-L functions in concert with Dicer-1 in catalyzing miRNA maturation and is required for reproductive development in Drosophila.

\section{Results and Discussion}

\section{Identification of R3D1}

Based on our previous studies of Dicer-2/R2D2 in the siRNA pathway (Liu et al. 2003), we hypothesized that Dicer-1 also functions in concert with an unknown dsRNA-binding protein in the miRNA pathway. 
Through a bioinformatics approach, we identified an open reading frame (ORF, CG6866) in the fly genome that showed considerable homology with R2D2 and RDE-4, an R2D2 homolog in C. elegans (Fig. 1A; Tabara et al. 2002; Liu et al. 2003). Furthermore, PSI-Blast ranked this ORF as the best hit among R2D2-like proteins in FlyBase, and vice versa. We named this protein R3D1 because it contained three putative dsRNA-binding domains (R3) and was later found to associate with Dicer-1 (D1) (Fig. 1; Kharrat et al. 1995). The R3D1 gene encodes two alternatively spliced proteins, R3D1-L (long; 465 amino acids) and R3D1-S (short; 419 amino acids) (Fig. 1A,B).

\section{R3D1-L interacts with Dicer-1 and AGO1}

To test physical association of endogenous Dicer-1 and R3D1, we performed coimmunoprecipitation (co-IP) experiments by using anti-Dicer-1 or anti-R3D1 antibodies in the cytosolic (S100) extracts of S2 cells. R3D1-L ( 55

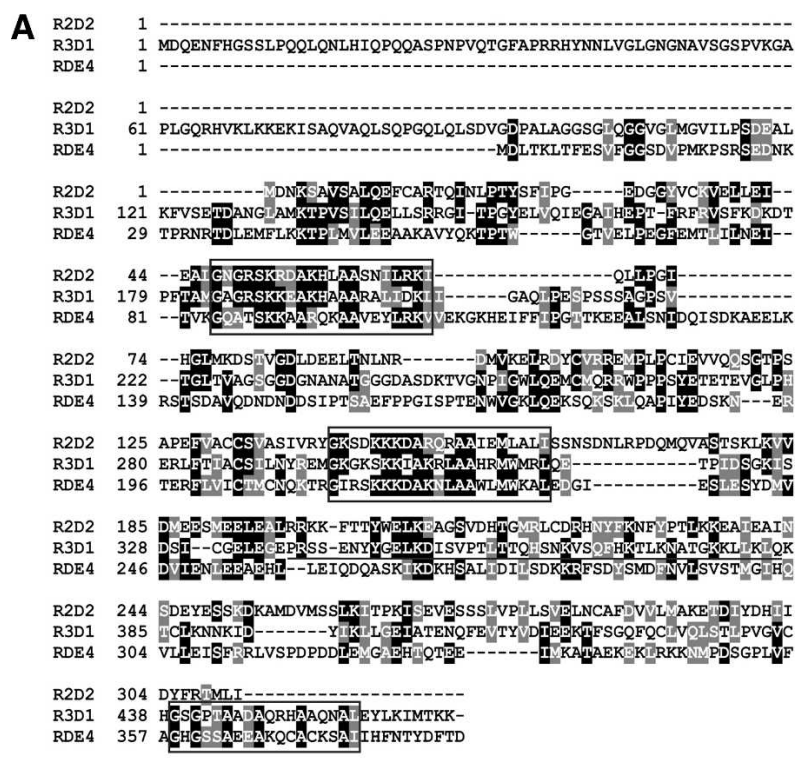

B

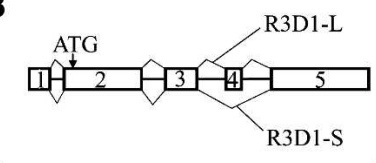

C
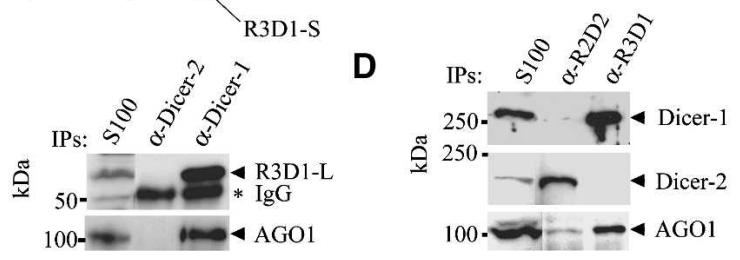

Figure 1. (A, top $)$ A sequence alignment of R3D1-L, R2D2, and RDE-4. Boxes refer to the most conserved motifs of three putative dsRNA-binding domains. (Bottom) The underlined region represents 46 amino acids encoded by exon 4 that is alternatively spliced to create R3D1-L and R3D1-S. $(B)$ A schematic diagram showing alternative splicing of R3D1-L and R3D1-S. Exons are shown as boxes with numbers inside. (C) Immunoprecipitations (IPs) were performed in S100 of S2 cells with anti-Dicer-1 or anti-Dicer-2 antibodies followed by Western blot using anti-R3D1 or anti-AGO1 antibodies. (D) IPs were performed with anti-R2D2 or anti-R3D1 antibodies followed by Western blots with corresponding antibodies to detect Dicer-1, Dicer-2, and AGO1. S100 lanes represent 5\% input for IPs.
$\mathrm{kDa})$ was present in the IPs of anti-Dicer-1 but not antiDicer-2 antibodies (Fig. 1C). We could not detect the presence of R3D1-S $(\sim 50 \mathrm{kDa})$ probably because it was absent or masked by the Immunoglobin (IgG) heavy chain (Fig. 1C). Reciprocal IP using anti-R3D1 antibody brought down Dicer-1 but not Dicer-2, whereas antiR2D2 antibody only brought down Dicer-2 (Fig. 1D). In addition, both Dicer-1 and R3D1 interacted with AGO1 (Fig. 1C,D), a critical component of miRISC /Okamura et al. 2004). These studies indicate that endogenous R3D1-L specifically associates with Dicer-1 and AGO1, which are key components of the initiation and effector complexes of the miRNA pathway.

\section{Purification of the miRNA-generating enzyme}

To study miRNA biogenesis, we purified the miRNAgenerating enzyme from S2 cell extracts by biochemical fractionation. A single peak of activity was observed on all columns tested and was followed throughout the purification. We performed Western blots to detect the presence of Dicer-1, R3D1, Dicer-2, and R2D2 among individual fractions following each step of purification. Both Dicer-1 and R3D1-L showed perfect correlation with the miRNA-generating activity after every chromatography step (Fig. 2; data not shown). This was not the case for R3D1-S, nor for Dicer-2/R2D2, which has been shown to generate siRNA in S2 cells (Fig. 2; Liu et al. 2003). Therefore, our previous and current results indicate that Dicer-1/R3D1-L and Dicer-2/R2D2 represent distinct initiation complexes of the miRNA and siRNA pathways in Drosophila cells.

\section{$R 3 D 1-L$ is required for miRNA biogenesis in vivo}

To determine if R3D1-L is required for miRNA biogenesis in vivo, we depleted Dicer-1, R3D1, or both in S2 cells by RNAi followed by Northern blotting to measure the levels of pre-bantam and bantam miRNA. Surprisingly, only R3D1-L ( $55 \mathrm{kDa})$, but not R3D1-S ( 50 kDa), protein was efficiently knocked down by treatment of R3D1 dsRNA (Fig. 3A, lanes 6,7). The R3D1 ( 1.1 kb) dsRNA should efficiently target both R3D1-L and R3D1-S mRNA, which differ by $138 \mathrm{nt}$. It was likely that R3D1-S comigrated with a cross-reacting protein on the Western blot. As shown previously (Okamura et al. 2004), depletion of AGO1, a key component of miRISC, resulted in a specific reduction of bantam miRNA in S2 cells (Fig. 3B, cf. lanes 3 and 1,2). On the other hand, knocking down Dicer-1 caused accumulation of pre-bantam but no reduction in bantam (Fig. 3B, cf. lanes 4 and 1,2). Targeting R3D1 produced a similar phenotype as Dicer-1 depletion (Fig. 3B, cf. lanes 4 and 6). When Dicer-1 and R3D1 were both targeted, there was a greater accumulation of pre-bantam and a modest reduction in bantam (Fig. 3B, lane 7). Since RNAi is transient and rarely a complete knockout, the lack of significant bantam reduction is probably because the remaining Dicer-1 is sufficient to maintain the level of miRNA production. Consistent with these results, the miRNA-generating activity was reduced by approximately twofold in Dicer1 - or R3D1-L-depleted cells and by $\sim 3.5$-fold in cells of double RNAi treatment (Supplementary Fig. 1). Thus, like Dicer-1, R3D1 is required for miRNA maturation in S2 cells. 

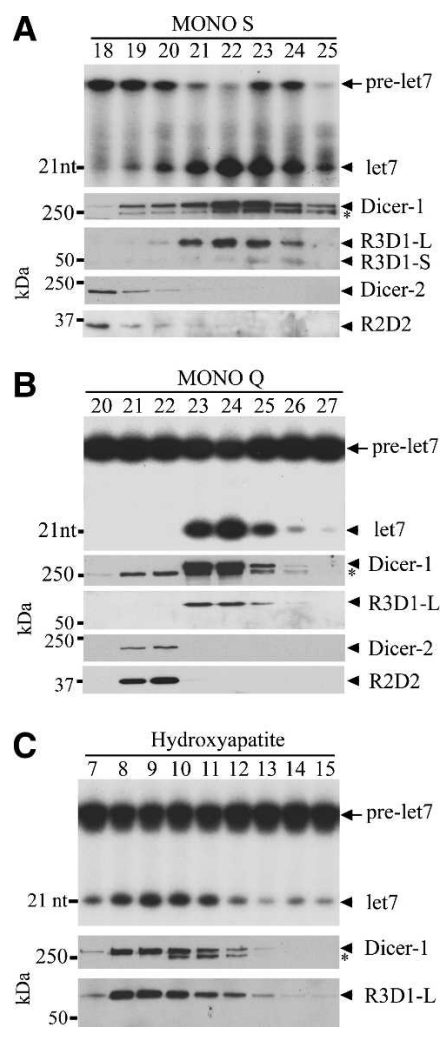

Figure 2. $(A-C)$ Purification of the miRNA-generating activity from S2 cell extracts by a five-step chromatography procedure (Supplemental Material). (Top) One microliter of each fraction was used for the pre-miRNA-processing assay. (Bottom) Western blots were performed with corresponding antibodies to detect Dicer-1, R3D1, Dicer-2, and R2D2 following Mono S $(A)$, Mono Q $(B)$, and Hydroxyapatite $(C)$ columns. The fractions 21-23 from the Mono S column were pooled and loaded onto the Mono Q column, whereas the fractions 23-24 from the Mono Q column were pooled and loaded onto the Hydroxyapatite column. The asterisks in Dicer-1 blots represent a cross-reacting protein or a degradation product of Dicer-1. Neither Dicer-2 nor R2D2 was detected in $C$ (data not shown).

\section{Dicer-1 and Dicer-2 have different substrate specificities and ATP requirements}

Previous genetic and biochemical studies have suggested that Dicer-1 and Dicer- 2 may possess different biochemical activities (Liu et al. 2003; Lee et al. 2004). It is also possible that associated proteins, such as R3D1-L and R2D2, can help define the functional specificity for Dicer-1 and Dicer-2. To distinguish the two possibilities, we expressed polyhistidine-tagged Dicer-1 or Dicer-1/ R3D1-L and Dicer-2 or Dicer-2/R2D2 recombinant proteins by using an insect cell expression system (Fig. 4A; Liu et al. 2003). These recombinant proteins were highly purified by Ni-NTA columns followed by SP-Sepharose and Q-Sepharose chromatography as previously described (Liu et al. 2003).

Despite sharing extensive sequence homology, Dicer-1 and Dicer-2 displayed different substrate specificities. As shown in Figure 4B, Dicer-1 demonstrated striking premiRNA processing activity, whereas miRNA generation was not detected for Dicer-2 at these concentrations. In contrast, Dicer- 2 was much more active than Dicer-1 in processing long dsRNA into siRNA. In addition, Dicer-1 and Dicer-2 had different ATP requirements. Like human Dicer, Dicer-1 or Dicer-1/R3D1-L generates miRNA or siRNA in an ATP-independent manner (Fig. 4C; data not shown), whereas Dicer-2 or Dicer-2/R2D2 required ATP hydrolysis for efficient siRNA production (Liu et al. 2003). Taken together, these reconstitution studies establish that Drosophila Dicer-1 and Dicer-2 are functionally distinct enzymes with different substrate specificities and ATP requirements.

\section{R3D1-L enhances miRNA production by Dicer-1}

Recombinant Dicer-1 and R3D1-L formed a stable complex and cofractionated on multiple columns (data not shown). Purified recombinant Dicer-1/R3D1-L complex was at least fivefold more active than Dicer-1 alone when measured in the pre-miRNA-processing assay (Fig. 4C). Consistent with this, addition of purified R3D1-L to Dicer-1 greatly enhanced its miRNA-generating activity in a dose-dependent manner (Fig. 4D). Purified R3D1-S has a similar role but to a lesser degree (data not shown). To compare the substrate affinity of Dicer-1 and Dicer1/R3D1-L, we performed gel-shift experiments in the absence of $\mathrm{Mg}^{2+}$, which blocked cleavage of pre-miRNA by Dicer-1 (Fig. 4E). Addition of R3D1-L to Dicer-1 greatly enhanced its affinity for pre-miRNA in a dose-dependent manner (Fig. 4F). These studies suggest that R3D1-L can enhance Dicer-1's miRNA-generating activity by increasing its substrate affinity.

\section{R3D1 mutant flies are defective for miRNA biogenesis}

To study the physiological function of R3D1 in flies, we obtained a piggyBac $(\mathrm{PB})$ fly strain in which the piggyBac transposon was inserted in the vicinity of the R3D1 gene (Bloomington, \#18371). By cloning and sequencing the

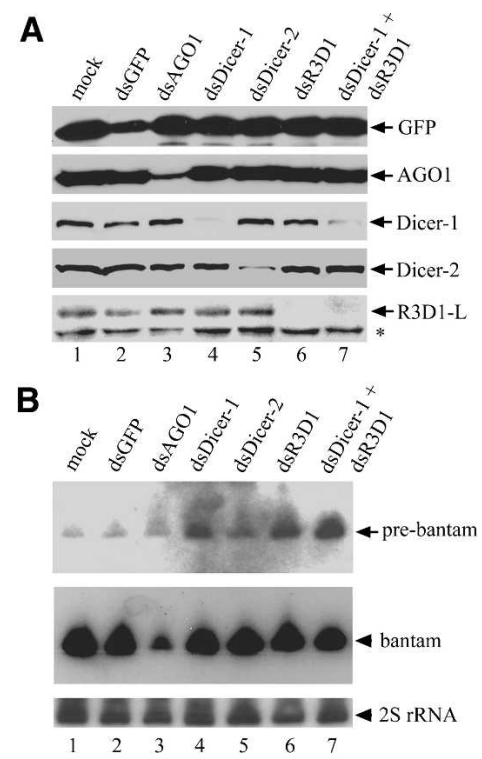

Figure 3. (A) Western blots were performed with corresponding antibodies to measure the levels of GFP, AGO1, Dicer-1, Dicer-2, and R3D1 in S2/GFP cells following various RNAi treatments (see information of various dsRNA in Supplementary Fig. 1). The asterisk refers to R3D1-S and a comigrating cross-reacting protein. $(B)$ Northern blots were performed to measure the levels of pre-bantam and bantam miRNA. 2S rRNA was used as loading control. 
A
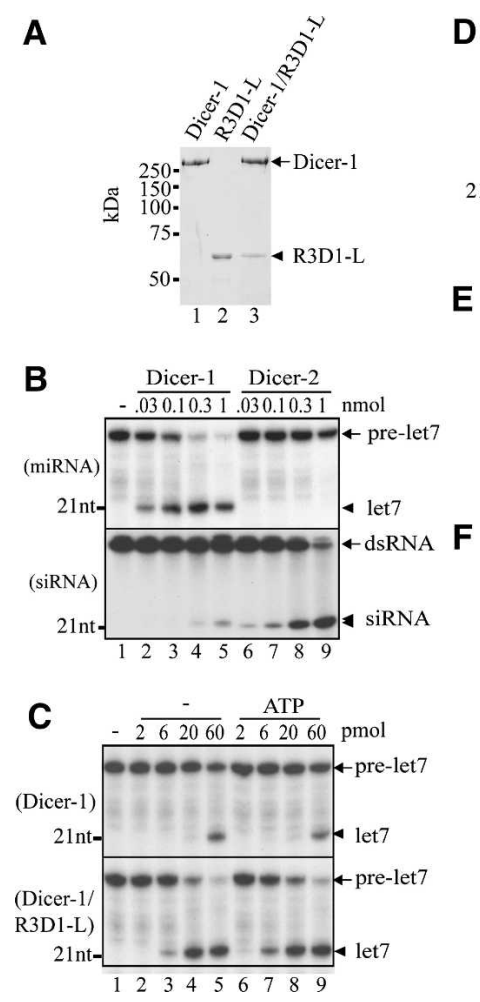

Figure 4. (A) A Coomassie-stained SDS-polyacrylamide gel (PAGE) showing purified recombinant Dicer-1, R3D1-L, and Dicer-1/ R3D1-L complex. (B) Dicer-1 and Dicer-2 display different substrate specificities. The pre-miRNA-processing (top) and siRNA-generating (bottom) assays were performed with various amounts of Dicer-1 (lanes 2-5) or Dicer-2 (lanes 6-9) (Liu et al. 2003). (C) Dicer-1 and Dicer-2 have different ATP requirements. The pre-miRNA-processing assays were performed with various amounts of Dicer-1 (top) or Dicer-1/R3D1-L (bottom) in the absence (lanes 2-5) or presence (lanes 6-9) of ATP. (D) R3D1-L enhances miRNA production by Dicer-1. The pre-miRNA-processing assays were performed with 25 pmol Dicer-1 alone (lane 2) or in combination with 30,100, or 300 pmol R3D1-L (lanes 3-5), or 300 pmol R3D1-L (lane 6). Lane 1 is a 21-nt marker. $(E) \mathrm{Mg}^{2+}$ is required for Dicer-1 cleavage of premiRNA. The pre-miRNA-processing assays were performed with buffer alone (lane 1), or with $1 \mathrm{nmol}$ Dicer-1 in $10 \mathrm{mM} \mathrm{Mg}^{2+}$ (lane 2) or $0.2 \mathrm{mM} \mathrm{Mg}^{2+}$ and $2.5 \mathrm{mM}$ EDTA (lane 3). (F) R3D1-L increases Dicer-1's affinity for pre-miRNA. The gel-shift assays were performed without $\mathrm{Mg}^{2+}$ in buffer alone (lane 1) or with $1 \mathrm{nmol}$ Dicer-1 alone (lane 2) or in combination with 1, 3, or $10 \mathrm{nmol} \mathrm{R3D1-L}$ (lanes 3-5), and 10 nmol R3D1-L (lane 6).

flanking sequences, we found that the PB-element was inserted within the first exon and $221 \mathrm{nt}$ upstream of the translational start codon of the R3D1 gene (Fig. 5A; Supplementary Fig. 2). The levels of R3D1-L and R3D1-S mRNA were much reduced in the homozygous flies when compared with wild type or heterozygotes by semiquantitative RT-PCR (Fig. 5A). However, we could not verify corresponding reductions in R3D1 proteins by Western blots due to masking by cross-reacting proteins. Nevertheless, this suggests that the PB-insertion creates a hypomorphic mutant allele of the R3D1 gene by attenuating its transcription.

To examine if miRNA biogenesis was defective in the $r 3 d 1^{P B}$ mutant flies, we compared the levels of premiR277 in wild-type, heterozygous, and homozygous adult flies. As shown by Northern blots, there was significant accumulation of pre-miR277 in both male and female homozygotes (Fig. 5B). Consistent with this, there was an approximately sixfold reduction in the miRNA-generating activity in the whole fly extracts of r3d $1^{P B} / r 3 d 1^{P B}$ mutant females (Fig. $5 \mathrm{C}$ ). The lack of reduction in mature miR277 can be explained by the fact that $r 3 d 1^{P B}$ is a partial loss-of-function allele. In addition, these data suggest that miRNA production may not be the rate-limiting step in the Drosophila miRNA pathway. Importantly, the miRNA-generating defect in the mutant lysates could be rescued by addition of recombinant R3D1-L, but not R3D1-S (Fig. 5D). Together, these results indicate that $r 3 d 1^{P B}$ mutant flies are defective for miRNA biogenesis.

\section{R3D1 deficiency causes severe sterility in male and female flies}

We suspected that $r 3 d 1$ mutant flies might display developmental phenotypes because miRNAs play essential
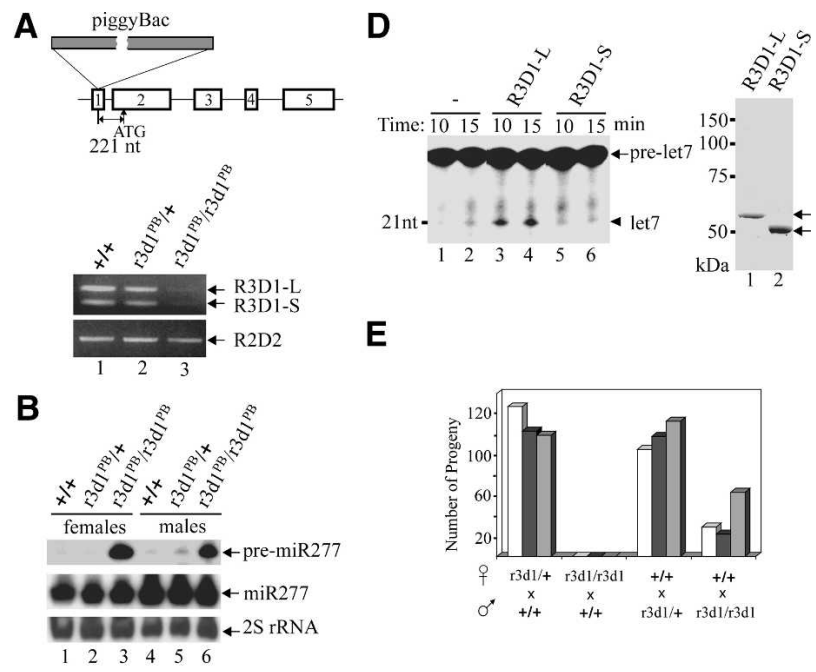

E

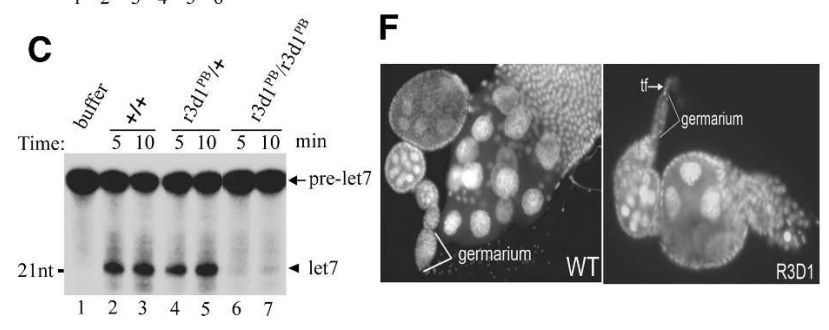

Figure 5. $(A$, top $) \mathrm{A}$ schematic diagram of the insertion site of piggyBac. (Bottom) The mRNA levels of R3D1-L, R3D1-S, and R2D2 were measured by semiquantitative RT-PCR in wild-type, heterozygous, and homozygous $r 3 d 1^{P B}$ female flies. $(B)$ The levels of premiR277 and miR277 were measured by Northern blots in wild-type, heterozygous, and homozygous $r 3 d 1^{P B}$ female (lanes 1-3) and male (lanes 4-6) flies. (C) The pre-miRNA-processing assays were performed with $5 \mu \mathrm{g}$ whole fly extracts prepared from wild-type (lanes 2,3 ), heterozygous (lanes 4,5), and homozygous (lanes 6,7) r $3 d 1^{P B}$ female flies. $(D$, left $)$ The pre-miRNA-processing assays were performed with $10 \mu \mathrm{g} r 3 d 1^{P B} / r 3 d 1^{P B}$ mutant extracts alone (lanes 1,2) or in combination with $35 \mathrm{ng}$ of recombinant R3D1-L (lanes 3,4) or R3D1-S (lanes 5,6). (Right) A Coomassie-stained SDS-PAGE showing purified recombinant R3D1-L and R3D1-S. (E) A graph showing infertility of homozygous $r 3 d 1^{P B}$ male and female flies. Three mating vials were set up for each cross (shown below the $X$-axis). The numbers of progeny are shown on the $Y$-axis. (F) Images of a wildtype (left) or $r 3 d 1^{P B} / r 3 d 1^{P B}$ mutant (right) ovariole stained with Hoechst dye to reveal the nuclei. (tf) Terminal filament. 
roles in animal development (Bartel 2004). Since $r 3 d 1^{P B}$ mutants survived to adulthood, we decided to examine their fertility by setting up crosses between $r 3 d 1^{P B}$ homozygous males or females and their wild-type counterparts. Interestingly, while $r 3 d 1^{P B}$ mutant females were completely sterile, the males were $\sim 60 \%-70 \%$ sterile when compared with the control crosses between heterozygotes and wild-type flies (Fig. 5E). To further analyze this phenotype, we dissected and examined the testes and ovaries from $r 3 d 1^{P B}$ mutant flies. Although mutant testes appeared normal, mutant ovaries contained a few maturing egg chambers and a shriveled germarium with few healthy germline stem cells (Fig. 5F). This is a classic "germ cell loss" phenotype because a few egg chambers can develop from primordial germ cells when the adult ovary first forms (McKearin and Ohlstein 1995). However, the mutant ovary did not sustain continuous egg chamber production since germline stem cells could not be properly maintained. These results indicate that R3D1 is required for normal reproductive development in male and female flies and suggest that specific miRNAs may play essential roles in maintaining germline stem cells in the fly ovary. We suspect that R3D1 deficiency, and hence the miRNA biogenesis defect, is far more severe in mutant testes and ovaries than other parts of the fly body.

\section{Dicers in flies, worms, and humans}

miRNA and siRNA can be viewed as two parallel branches of the RNAi pathway. Our biochemical studies demonstrate that Dicer-1/R3D1-L and Dicer-2/R2D2 are used as distinct initiation complexes for the miRNA and siRNA pathways, respectively, in Drosophila cells. The same concept can also be applied to species containing a single Dicer, such as C. elegans and humans. In C. elegans, DCR-1/RDE-4 functions as the initiation complex for the siRNA pathway. However, RDE-4 is not required for the miRNA pathway. It is likely that DCR-1 functions in concert with another dsRNA-binding protein in the miRNA pathway.

By reconstitution, we establish that Drosophila Dicer- 1 and Dicer-2 enzymes are functional distinct enzymes with different ATP requirements and substrate specificities. Like Dicer-1, human Dicer generates miRNA or siRNA in an ATP-independent manner (Provost et al. 2002; Zhang et al. 2002). Like Dicer-2, the $C$. elegans DCR-1 requires ATP hydrolysis for efficient siRNA production (Hutvagner et al. 2001; Tabara et al. 2002; Liu et al. 2003). While Dicer-1 is more suited for processing pre-miRNA, Dicer-2 favors long dsRNA as its ideal substrate. Thus, it will be important to identify the sequence and structural features that determine the evolutionary and functional differences between Dicer-1 and Dicer-2.

\section{Does Dicer-1/R3D1-L facilitate miRISC assembly?}

The Dicer-2/R2D2 complex not only generates siRNA, but also binds siRNA and facilitates siRNA loading onto the siRISC complex (Liu et al. 2003; Tomari et al. 2004). It is likely that the Dicer-1/R3D1-L complex plays a similar role in facilitating miRNA loading onto the miRISC complex. Consistent with this hypothesis, recombinant Dicer-1/R3D1-L complex efficiently binds to the synthetic miRNA/miR* duplex (data not shown).
Since the majority of the $\mathrm{miRNA} / \mathrm{miR}^{\star}$ duplexes have different stability at the two ends, this thermodynamic asymmetry is believed to cause preferential loading of miRNA onto miRISC and destruction of the miR ${ }^{\star}$ strand (Tomari et al. 2004). It is reasonable to speculate that the Dicer-1/R3D1-L complex also functions as a sensor for the asymmetry of nascent $\mathrm{miRNA} / \mathrm{miR}^{\star}$ duplex and helps to select the miRNA strand as the guide RNA for miRISC. Since R3D1-L interacts with both Dicer-1 and AGO1, it may play a similar role as R2D2 by bridging the initiation and effector steps of the miRNA pathway.

\section{Partnerships of RNase III enzymes and dsRNA-binding proteins}

While Dicer-2/R2D2 cleaves long dsRNA into siRNA, Drosha/Pasha (DGCR8 in human) and Dicer-1/R3D1-L catalyze sequential steps of miRNA biogenesis, processing of pri-miRNA into pre-miRNA and of pre-miRNA into miRNA, respectively (Liu et al. 2003; Denli et al. 2004; Gregory et al. 2004; Han et al. 2004; Landthaler et al. 2004). Although R2D2 does not regulate siRNA production, it facilitates the role of Dicer-2 in loading siRNA onto siRISC (Liu et al. 2003). While Pasha ${ }^{\text {fly }}$ / DGCR8 $8^{\text {human }}$ is essential for Drosha to process primiRNA (Gregory et al. 2004; Han et al. 2004), R3D1-L greatly enhances miRNA generation by Dicer-1. Taken together, these studies indicate that all known RNase III enzymes (Drosha, Dicer-1, and Dicer-2) are paired with specific dsRNA-binding proteins (Pasha, R3D1-L, and R2D2) in catalyzing small RNA biogenesis and/or function in Drosophila. It remains uncertain if the same pattern will repeat in other species.

\section{Materials and methods}

Cloning, expression, and purification of recombinant proteins The cDNAs of Dicer-1, R3D1-L, and R3D1-S were cloned from total RNA of S2 cells by RT-PCR using the RLM-RACE kit from Ambion. Polyhistidine (His)-tagged recombinant proteins were expressed in insect cells by using the BAC-to-BAC baculovirus expression system (Invitrogen) as described (Liu et al. 2003). Both R3D1-L and R3D1-S were Histagged at the $\mathrm{N}$ terminus, whereas Dicer-1 was double His-tagged at both ends.

\section{RNAi and Northern blots}

In a 24 -well dish, $10^{6} \mathrm{~S} 2 / \mathrm{GFP}$ cells were soaked in $0.5 \mathrm{~mL}$ serum-free media (Invitrogen) containing 10-15 $\mu \mathrm{g}$ dsRNA for $36 \mathrm{~h}$ followed by a second dose for another 36 h. Following RNAi treatment, whole cell lysates were prepared in $2 \%$ SDS buffer for Western blotting, and total RNA was isolated using TRIzol (Invitrogen) for Northern blotting as previously described (Aravin et al. 2003; Liu et al. 2003). For Northern blotting, a DNA oligo, 5'-GGCCGACAAAATCAGCTTTCAAAATGAT CTCACTTGT-3', was used for bantam (S2 cells); a DNA oligo, 5'-TAC AACCCTCAACCATATGTAGTCCAAGCA-3', for 2SrRNA; and an RNA oligo, 5'-UCGUACCAGAUAGUGCAUUUUCA-3', for miR277 (flies). All probes were $5^{\prime}$-end-labeled with $\gamma^{-32} \mathrm{P}$ by $\mathrm{T} 4$ polynucleotide kinase.

Pre-miRNA-processing and gel-shift assays A 61-nt synthetic pre-let7, 5'-UGAGGUAGUAGGUUGUAUAGU AGUAAUUACACAUCAUACUAUACAAUGUGCUAGCUUUCUU-3' (Dharmacon), was $5^{\prime}$-end-labeled by $\gamma^{-32} \mathrm{P}$ by polynucleotide kinase (NEB). In the pre-miRNA-processing assay, $4 \times 10^{4} \mathrm{cpm}$ pre-let 7 was incubated with extracts or recombinant proteins in $110 \mathrm{mM}$ KOAc, $10 \mathrm{mM}$

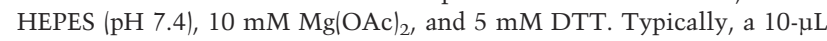
reaction was performed at $30^{\circ} \mathrm{C}$ for $30 \mathrm{~min}$ in the absence or presence of a 1× ATP-regenerating system (1 mM ATP, $30 \mathrm{mM}$ creatine phosphate 
[Fluka], and $30 \mathrm{U}$ creatine phosphokinase [Sigma]). The gel-shift assay was performed as the processing assay except for using $10^{5} \mathrm{cpm}$ pre-let7 in the presence of $0.2 \mathrm{mM} \mathrm{Mg}^{2+}$ and $2.5 \mathrm{mM}$ EDTA. The reaction mixture was resolved by a $5 \%$ native PAGE.

\section{Antibodies and co-IP}

The anti-R3D1 and anti-AGO2 antibodies were raised in rabbits against full-length recombinant R3D1-L and a truncated AGO2. The antiDicer-2 and anti-R2D2 antibodies have been described (Liu et al. 2003). The anti-Dicer-1 antibodies were a gift from Dr. Gregory Hannon (Cold Spring Harbor Laboratory, Cold Spring Harbor, NY) (used for IPs) or purchased from Abcam (used for Western blots). The anti-GFP and antiAGO1 antibodies were from Molecular Probes and Abcam, respectively. Co-IP experiments were carried out in $500 \mu \mathrm{L}$ volume by incubating $2 \mathrm{mg}$ of S100, $10 \mu \mathrm{L}$ of affinity-purified antibodies, and $10 \mu \mathrm{L}$ protein A-Sepharose beads (Santa Cruz) for $2 \mathrm{~h}$ in RISC buffer [110 mM KOAc, $10 \mathrm{mM}$ HEPES at $\mathrm{pH} 7.4,2 \mathrm{mM} \mathrm{Mg}(\mathrm{OAc})_{2}, 5 \mathrm{mM}$ DTT, $\left.0.05 \% \mathrm{NP}-40\right]$. The beads were washed six times with $1 \mathrm{~mL}$ RISC buffer containing $50 \mathrm{mM} \mathrm{NaCl}$, and boiled in $2 \times$ SDS sample buffer prior to Western blot analysis.

\section{$R T-P C R$}

Total RNA was isolated from 30 female flies by TRIzol (Invitrogen). RT-PCR reactions were performed using the SuperScript One-Step RTPCR kit from Invitrogen. In brief, 100 ng RNA was used as template with one round of reverse transcription and 30 cycles of PCR. The primers included 5'-GGGCAAAAGCAAGAAGATAG-3' and 5'-GCGGCCGCT CACTTCTTGGTCATGATCTTC-3' for amplifying R3D1-L (508 bp) and R3D1-S (370 bp), or 5'-CATATGGATAACAAGTCAGCCGTATC-3' and 5'-AGAACGCGGCCGCTTAGTAGGTGGTAAATTTCTTTCTG-3' for amplifying R2D2 $(631 \mathrm{bp})$. All PCR products were resolved by $1.5 \%$ agarose gel electrophoresis.

\section{Acknowledgments}

We thank Dr. Gregory Hannon for reagents; Dr. Phillip Zamore for sharing unpublished results; Zhengzheng Li, Wenhua Gao, and Dr. Po Chen for technical assistance; and Tim Rand and Drs. Michael Brown, James Chen, Yi Liu, Zain Paroo, Michael Rosen, and Xiaodong Wang for discussion and critical reading of the manuscript. Q.L. is a W.A. "Tex" Moncrief Jr. Scholar in Medical Research and a Damon Runyon Scholar supported by the Damon Runyon Cancer Research Foundation (DRS-43).

\section{Note added in proof}

R3D1 has recently been independently identified by two other labs and named Loquacious (Förstemann et al. 2005; Saito et al. 2005).

\section{References}

Aravin, A.A., Lagos-Quintana, M., Yalcin A., Zavolan, M., Marks, D., Snyder, B., Gaasterland, T., Meyer, J., and Tuschl, T. 2003. The small RNA profile during Drosophila melanogaster development. Dev. Cell 5: 337-350.

Bartel, D.P. 2004. MicroRNAs: Genomics, biogenesis, mechanism, and function. Cell 116: 281-297.

Bernstein, E., Caudy, A.A., Hammond, S.M., and Hannon, G.J. 2001. Role for a bidentate ribonuclease in the initiation step of RNA interference. Nature 409: 363-366.

Bohnsack, M.T., Czaplinski, K., and Gorlich, D. 2004. Exportin 5 is a RanGTP-dependent dsRNA-binding protein that mediates nuclear export of pre-miRNAs. RNA 10: 185-191.

Cullen, B.R. 2004. Transcription and processing of human microRNA precursors. Mol. Cell 16: 861-865.

Denli, A.M., Tops, B.B., Plasterk, R.H., Ketting, R.F., and Hannon, G.J. 2004. Processing of primary microRNAs by the Microprocessor complex. Nature 432: 231-235.

Förstemann, K., Tomari, Y., Du, T., Vagin, V.V., Denli, A.M., Bratu, D.P., Klattenhoff, C., Theurkauf, W.E., and Zamore, P.D. 2005. Normal microRNA maturation and germ-line stem cell maintenance requires loquacious, a double-stranded RNA-binding domain protein. PLOS Biol. 3: e236.

Gregory, R.I., Yan, K.P., Amuthan, G., Chendrimada, T., Doratotaj, B., Cooch, N., and Shiekhattar, R. 2004. The Microprocessor complex mediates the genesis of microRNAs. Nature 432: 235-240.

Hammond, S.M., Bernstein, E., Beach, D., and Hannon, G.J. 2000. An RNA-directed nuclease mediates post-transcriptional gene silencing in Drosophila cells. Nature 404: 293-296.

Hammond, S.M., Boettcher, S., Caudy, A.A., Kobayashi, R., and Hannon, G.J. 2001. Argonaute2, a link between genetic and biochemical analyses of RNAi. Science 293: 1146-1150.

Han, J., Lee, Y., Yeom, K.H., Kim, Y.K., Jin, H., and Kim, V.N. 2004. The Drosha-DGCR8 complex in primary microRNA processing. Genes \& Dev. 18: 3016-3027.

Hannon, G.J. 2002. RNA interference. Nature 418: 244-251.

Hutvagner, G., McLachlan, J., Pasquinelli, A.E., Balint, E., Tuschl, T., and Zamore, P.D. 2001. A cellular function for the RNA-interference enzyme Dicer in the maturation of the let-7 small temporal RNA. Science 293: 834-838.

Kharrat, A., Macias, M.J., Gibson, T.J., Nilges, M., and Pastore, A. 1995. Structure of the dsRNA binding domain of E. coli RNase III. EMBO I. 14: 3572-3584.

Landthaler, M., Yalcin, A., and Tuschl, T. 2004. The human DiGeorge syndrome critical region gene 8 and its $D$. melanogaster homolog are required for miRNA biogenesis. Curr. Biol. 14: 2162-2167.

Lee, Y., Ahn, C., Han, J., Choi, H., Kim, J., Yim, J., Lee, J., Provost, O., Radmark, P., Kim, S., et al. 2003. The nuclear RNase III Drosha initiates microRNA processing. Nature 425: 415-419.

Lee, Y.S., Nakahara, K., Pham, J.W., Kim, K., He, Z., Sontheimer, E.J., and Carthew, R.W. 2004. Distinct roles for Drosophila Dicer-1 and Dicer-2 in the siRNA/miRNA silencing pathways. Cell 117: 69-81.

Liu, Q., Rand, T.A., Kalidas, S., Du, F., Kim, H.E., Smith, D.P., and Wang, X. 2003. R2D2, a bridge between the initiation and effector steps of the Drosophila RNAi pathway. Science 301: 1921-1925.

Lund, E., Guttinger, S., Calado, A., Dahlberg, J.E., and Kutay, U. 2004 Nuclear export of microRNA precursors. Science 303: 95-98.

McKearin, D. and Ohlstein, B. 1995. A role for the Drosophila bag-ofmarbles protein in the differentiation of cystoblasts from germline stem cells. Development 121: 2937-2947.

Okamura, K., Ishizuka, A., Siomi, H., and Siomi, M.C. 2004. Distinct roles for Argonaute proteins in small RNA-directed RNA cleavage pathways. Genes \& Dev. 18: 1655-1666.

Provost, P., Dishart, D., Doucet, J., Frendewey, D., Samuelsson, B., and Radmark, O. 2002. Ribonuclease activity and RNA binding of recombinant human Dicer. EMBO J. 21: 5864-5874.

Saito, K., Ishizuka, A., Siomi, H., and Siomi, M.C. 2005. Processing of pre-microRNAs by the Dicer-1-loquacious complex in Drosophila cells. PLoS Biol. 3: e235.

Tabara, H., Yigit, E., Siomi, H., and Mello, C.C. 2002. The dsRNA binding protein RDE-4 interacts with RDE-1, DCR-1, and a DExH-box helicase to direct RNAi in C. elegans. Cell 109: 861-871.

Tang, G. 2005. siRNA and miRNA: An insight into RISCs. Trends Biochem. Sci. 30: 106-114.

Tomari, Y. and Zamore, P.D. 2005. Perspective: Machines for RNAi. Genes \& Dev. 19: 517-529.

Tomari, Y., Matranga, C., Haley, B., Martinez, N., and Zamore, P.D. 2004. A protein sensor for siRNA asymmetry. Science 306: $1377-$ 1380.

Yi, R., Qin, Y., Macara, I.G., and Cullen, B.R. 2003. Exportin-5 mediates the nuclear export of pre-microRNAs and short hairpin RNAs. Genes \& Dev. 17: 3011-3016.

Zhang, H., Kolb, F.A., Brondani, V., Billy, E., and Filipowicz, W. 2002. Human Dicer preferentially cleaves dsRNAs at their termini without a requirement for ATP. EMBO T. 21: 5875-5885.

Zhang, H., Kolb, F.A., Jaskiewicz, L., Westhof, E., and Filipowicz, W. 2004. Single processing center models for human Dicer and bacterial RNase III. Cell 118: 57-68. 


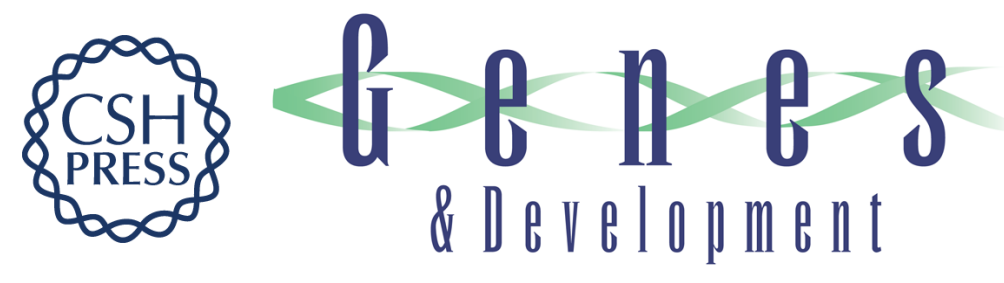

\section{Dicer-1 and R3D1-L catalyze microRNA maturation in Drosophila}

Feng Jiang, Xuecheng Ye, Xiang Liu, et al.

Genes Dev. 2005, 19:

Access the most recent version at doi:10.1101/gad.1334005

Supplemental

Material

References

License

Email Alerting Service
http://genesdev.cshlp.org/content/suppl/2005/06/28/gad.1334005.DC1

This article cites 30 articles, 13 of which can be accessed free at: http://genesdev.cshlp.org/content/19/14/1674.full.html\#ref-list-1

Receive free email alerts when new articles cite this article - sign up in the box at the top right corner of the article or click here.

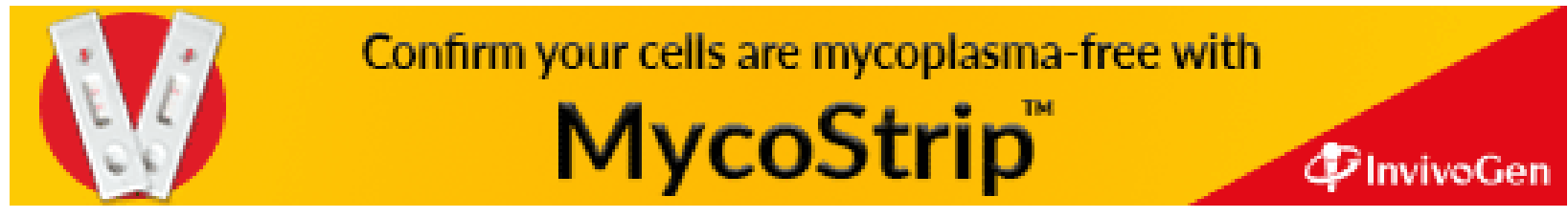

